\title{
AVALIAÇÃo MICROBIOLÓGICA E PARASITOLÓGICA DE ALFACES (Lactuca sativa L) COMERCIALIZADAS EM FEIRAS LIVRES NO MUNICÍPIO DE SOBRAL - CE
}

\author{
Maria Gleiciane Soares COUTINHO ${ }^{1, *}$ \\ Chayanna da Silva FERREIRA ${ }^{2}$ \\ Andréa Maria NEVES 3 \\ Francisca Rosilane Lucas ALVES ${ }^{4}$ \\ Francisco Fábio Pereira de SOUZA ${ }^{5}$ \\ Raquel Oliveira dos Santos FONTENELLE ${ }^{6}$
}

\author{
${ }^{1-6}$ Universidade Estadual Vale do Acaraú \\ *Autora correspondente:gleycy-soares1@hotmail.com
}

Recebido em: 23/04/2015 - Aprovado em: 25/08/2015 - Disponibilizado em: 30/10/2015

\begin{abstract}
RESUMO
A alface (Lactuca sativa L), pertencente à família Asteraceae, é a hortaliça folhosa mais consumida no Brasil. Esta possui baixo valor calórico e alto valor nutritivo por isso é empregada em diversos tipos de dietas. Para manter suas propriedades deve ser consumida in natura, sendo um importante veículo de contaminação. O presente trabalho teve como objetivo avaliar a qualidade microbiológica e parasitológica de alfaces (Lactuca sativa $\mathrm{L}$ ) comercializadas em feiras livres do município de Sobral - CE. Foram coletadas quatro amostras de alface da variedade crespa em três feiras livres distintas, perfazendo um total de doze amostras. As análises foram realizadas no Laboratório de Microbiologia da Universidade Estadual Vale do Acaraú. A análise microbiológica foi realizada pela determinação do Número Mais Provável (NMP) de Coliformes totais e termotolerantes através do método de fermentação em tubos múltiplos, sendo utilizada para a contagem padrão em placas a técnica do Pour Plate e teste do ImVic para identificação de espécies da família Enterobactericeae. A metodologia empregada para análise parasitológica foi à lavagem seguida de sedimentação e centrifugação. Das amostras analisadas 100\% apresentaram índices de Coliformes termotolerantes acima do permitido pela legislação, sendo identificadas dez espécies de bactérias da família Enterobactericeae. Em $91 \%$ das amostras da análise parasitológica observou-se presença de parasitas, tais como, Ascaris sp. e Entamoeba sp. Considerando os resultados, evidencia-se baixa qualidade higiênico-sanitária, sendo necessária à atenção dos produtores e consumidores a correta higienização, a fim de diminuir a transmissão de certas doenças veiculadas por alimentos contaminados.
\end{abstract}

PALAVRAS CHAVE: Ascaris sp. coliformes.Escherichia coli. Enterobacteriaceae. higiênico-sanitária.

\begin{abstract}
The lettuce (Lactuca sativa $\mathrm{L}$ ) belonging to the family Asteraceae, is a leafy vegetable most consumed in Brazil. This has low calorie and high nutritional value so it is used in various types of diets. To maintain their properties must be consumed fresh, is an important vehicle of contamination. This study aimed to evaluate the microbiological and parasitological quality of lettuce (Lactuca sativa L) sold in fairs free of the city of Sobral - CE. Four lettuce samples of curly variety were collected in three different fairs, making a total of twelve samples. The analysis were performed at the Microbiology Laboratory of the State University Valley Acaraú. Microbiological analysis was performed by determining the Most Probable Number (MPN) of total coliforms and thermotolerant through the fermentation method in multiple tube and is used for the standard plate count Technique Pour Plate and ImVic test for species identification Enterobactericeae family. The methodology used for parasitological analysis was then to wash sedimentation and centrifugation. $100 \%$ of the analyzed samples showed fecal coliform levels above those permitted by law, identified ten species of bacteria Enterobactericeae family. $91 \%$ of the parasitological analysis of samples was observed the presence of parasites such as Ascaris sp. and Entamoeba sp. Considering the results, it is evident low sanitary conditions, being necessary to the attention of producers and consumers proper hygiene in order to reduce the transmission of certain diseases transmitted by contaminated food.
\end{abstract}

KEYWORDS: Ascaris sp. coliforms.Escherichia coli.Enterobactericeae. low sanitary. 


\section{INTRODUÇÃO}

A alface (Lactuca sativa $\mathrm{L}$ ), pertencente à família Asteraceae, é a hortaliça folhosa mais consumida no Brasil. Por possuir

alto valor nutritivo, baixo valor calórico eser importante fonte de vitaminas e sais minerais é empregada em diversos tipos de dietas(FERNANDES et al., 2002; NASCIMENTO et al., 2005). No entanto para manter suaspropriedades deve ser consumida in natura (MAISTRO, 2001).

O consumo de alimentos crus representa alto risco à saúde humana, pois a presença de agentes infecciosos de origem fecal pode torna-se um vinculo transmissor de diversas doenças (PERES JUNIOR; GONTIJO; SILVA, 2012). A ocorrência de micro-organismos de origem fecal em alimentos podem fornecer informações relacionadas à provável presença de patógenos, sobre a deterioração potencial do alimento, além de indicar condições sanitárias inadequadas (FRANCO; LANDGRAF, 2008).

A contaminação de alfaces pode ocorrer de diversas formas, sendo as principais, pela utilização de água contaminada por fezes de origem humana, por falta de higiene no momento da manipulação dos alimentos ou pela contaminação do solo por uso de adubo orgânico com dejetos fecais (SANTANA et al., 2006). Outros fatores também podem estar relacionadosà contaminação dessas hortaliças, tais como, más condições de cultivo, colheita, armazenamento, transporte e acondicionamento(COSTANTIN; GELATTI; DOS SANTOS, 2013).

Segundo Xavier (2009), os alimentos comercializados em feiras livres apresentam alto grau de contaminação por ficarem expostos ao ar livre, estando susceptíveis a sofrer alterações biológicas, devido às ações dos diferentes organismos atuando sobre eles,por causa do pouco controle bromatológico ou da manipulação inadequada. Também podem estar expostas a contaminação por micro-organismos e insetos devido a poluição urbana.

O monitoramento a contaminação parasitológica e microbiológica em hortaliças e manipuladores de alimentos nesses locais, tornaria possível um sistema preventivo e dinâmico para a qualidade das hortaliças consumidas pela população, fornecendo dados sobre as condições higiênico-sanitárias desses produtos para a Saúde Pública e Vigilância Sanitária (SILVA; SILVA; SILVA, 2010).

Diante disso, o objetivo deste trabalho foi analisar a qualidade microbiológica e parasitológica de alfaces (Lactuca sativa $\mathrm{L}$ ) comercializadas em feiras livres no município de Sobral - CE. 


\section{MATERIAL E MÉTODO}

\subsection{Análise microbiológica}

Foram coletados dois pés de alface da variedade crespa, em três feiras livres do município de Sobral - CE, entre março de 2014 a março de 2015, sendo realizadas quatro coletas em cada estabelecimento, perfazendo um total de doze amostras. As hortaliças foram acondicionadas em sacos plásticos e encaminhadas ao Laboratório de Microbiologia da Universidade Estadual Vale do Acaraú, onde se realizaram as análises.

Pesou-se $25 \mathrm{~g}$ de alface as quais homogeneizadas com $225 \mathrm{~mL}$ de solução salina $(0,85 \%)$ estéril, sendo esta a diluição $10^{-1}$, em seguida $1 \mathrm{~mL}$ desta diluição foi dissolvida em $9 \mathrm{~mL}$ de solução salina, constituindo a diluição $10^{-2}$, procedendo assim até a diluição $10^{-3}$. Este procedimento foi feito em todas as amostras obtidas durante as analises microbiológicas.

O Número Mais Provável (NMP) de Coliformes Totais (CT) e Coliformes Termotolerantes (CTT) foi determinado através da técnica dos tubos múltiplos (BLODGETT, 2003). O teste foi realizado em três etapas distintas: prova presuntiva, prova para determinação de coliformes totais e termotolerantes e prova bioquímica (FENG; WEAGENT; GRANTE, 2002).

Para o teste presuntivo utilizou-se o Caldo Lactosado com tubos de durhan invertidos, sendo utilizadas três diluições das amostras com repetições de cinco tubos para cada diluição. Na primeira série de tubos, foram inoculados $1 \mathrm{~mL}$ da diluição $10^{-1} \mathrm{em} 10$ $\mathrm{mL}$ de Caldo Lactosado. A segunda série de cinco tubos foi inoculada com $1 \mathrm{~mL}$ da diluição $10^{-2}$ e a terceira série com $1 \mathrm{~mL}$ da diluição $10^{-3}$. Em seguida, os tubos foram incubados em estufa bacteriológica a $35^{\circ}$ por 48 horas. Foram considerados positivos os tubos de Caldo Lactosado que apresentaram produção de gás com formação de bolhas no durhan e turvação do meio (JAKABI; FRANCO, 1991).

Para a identificação de Coliformes Totais foram retiradas alíquotas dos tubos positivos de lactosado e inoculados em Caldo Bile Verde Brilhante (BVB) que foram incubados em estufa a $35^{\circ} \mathrm{C}$ por 48 horas. A quantificação de Coliformes Termotolerantes foi feita retirando-se alíquotas com auxílio de uma alça de níquel cromo dos tubos de lactosado positivos e inoculando-se em tubos com Caldo Escherichia coli (EC) e tubos de durham invertidos e posterior incubação em banho-maria a $45^{\circ} \mathrm{C}$ por 48 horas.

Para isolamento e identificação de $E$. coli, foram retiradas alíquotas dos tubos positivos de EC e semeados com alça de níquel cromo em placas contendo meio Eosin Methylene Blue Ágar (EMB) e incubados em estufa a $35^{\circ} \mathrm{C}$ por 24 horas. As colônias com características positivas para E. coli, de coloração verde brilhante, foram isoladas em Tryptic Soy Ágar (TSA) e identificados 
através do teste do ImVic (KONEMAM et al., 2008).

Procedeu-se também a contagem padrão em placas utilizada para quantificar as bactérias aeróbias mesófilas, esta foi feita através da técnica do "Pour Plate", no qual, foram retiradas $1 \mathrm{~mL}$ de cada uma das 3 diluições das amostras e adicionadas a $15 \mathrm{~mL}$ de Plate Count Ágar (PCA). O inóculo foi misturado ao meio de cultura movimentando suavemente as placas numa superfície plana, com movimentos em forma de oito. Após a completa solidificação do meio de cultura as placas foram incubadas em estufa a $35^{\circ} \mathrm{C}$, por 24 horas. O procedimento foi realizado em duplicata para todas as diluições (SILVA; JUNQUEIRA; SILVEIRA, 2001).

\subsection{Análise parasitológica}

A metodologia utilizada para análise parasitológica nas alfaces foi à lavagem seguida de sedimentação e centrifugação. Quando se pesou $50 \mathrm{~g}$ alface separando as folhas e descartando aquelas que estavam deterioradas, bem como o talo. As folhas, já pesadas, foram mergulhadas em bandeja contendo solução de detergente neutro $(5 \mathrm{~mL}$ de detergente diluído em 1 litros de solução fisiológica a 0,9\%). Com o auxílio de um pincel $\left(\mathrm{n}^{\circ}\right.$ 18), as folhas foram lavadas de acordo com a técnica descrita por Oliveira e Germano (1992) e depois descartadas.
O líquido obtido foi filtrado em gaze de oito dobras e recolhido em um cone Imhoff onde foi deixado por 24 horas para a sedimentação. Finalizado este processo, o líquido sobrenadante foi desprezado e os 10 $\mathrm{mL}$ finais foram centrifugados a $2.500 \mathrm{rpm}$ (velocidade de centrifugação em rotações por minuto) durante cinco minutos, posteriormente, o líquido sobrenadante foi descartando e com o auxílio de uma pipeta, uma gota do sedimento resultante foi colocada em uma lâmina para microscopia, corado com lugol e analisado ao microscópio óptico com a utilização das objetivas nos aumentos de 10X e 40X.

\section{RESULTADOS E DISCUSSÃO}

Os resultados obtidos dasamostras analisadas para coliformes totais variaram de $3,1 \times 10^{3} \mathrm{NMP} / \mathrm{g}$ a $>1,6 \times 10^{6} \mathrm{NMP} / \mathrm{g}$ com média de $9,9 \times 10^{4} \mathrm{NMP} / \mathrm{g}$, para coliformes termotolerantes apresentou valor médio de $8,2 \times 10^{4} \mathrm{NMP} / \mathrm{g}$ variando de $3,1 \times 10^{3} \mathrm{NMP} / \mathrm{g}$ a $2,2 \times 10^{5} \mathrm{NMP} / \mathrm{g}$ (Tabela 1 ).

Teixeira et al. (2013) em trabalho realizado com hortaliças comercializadas na cidade de Juazeiro do Norte - CE, demostrou que todas as amostras analisadas apresentaram índices de contaminação iguais ou superiores a 2,8x10 NMP/g, resultados inferiores ao encontrado no presente trabalho.Diferentemente dos resultados obtidos por Bobco et al. (2011) em estudos 
que avaliaram as condições higiênicas de alfaces comercializadas na cidade de Erechim - RS, onde observou-se que todas as alfaces analisadas apresentam padrões aceitáveis para o consumo humano em relação a coliformes termotolerantes.

Tabela 1 - Número Mais Provável (NMP) de coliformes totais (CT), coliformes termotolerantes (CTT), contagem de bactérias aeróbias mesófilas em alfaces comercializadas em feiras livres no município de Sobral - CE.

\begin{tabular}{cccc}
\hline $\begin{array}{c}\text { AMOSTRAS } \\
\text { Ponto A }\end{array}$ & $\begin{array}{c}\text { NMP/g } \\
\text { de CT* }\end{array}$ & $\begin{array}{c}\text { NMP/g } \\
\text { de } \\
\text { CTT** }\end{array}$ & $\begin{array}{c}\text { Bactérias } \\
\text { mesófilas } \\
\text { (UFC/g) }\end{array}$ \\
\hline $\mathbf{1}$ & $3,5 \times 10^{4}$ & $3,5 \times 10^{4}$ & $4,5 \times 10^{4}$ \\
$\mathbf{2}$ & $>1,6 \times 10^{5}$ & $1,6 \times 10^{5}$ & $3,0 \times 10^{5}$ \\
$\mathbf{4}$ & $>1,6 \times 10^{6}$ & $2,2 \times 10^{5}$ & $2,3 \times 10^{5}$ \\
Ponto B & $5,8 \times 10^{3}$ & $5,8 \times 10^{3}$ & $7,7 \times 10^{5}$ \\
$\mathbf{1}$ & $2,4 \times 10^{4}$ & $7,9 \times 10^{3}$ & $1,4 \times 10^{5}$ \\
$\mathbf{2}$ & $3,1 \times 10^{3}$ & $3,1 \times 10^{3}$ & $2,4 \times 10^{5}$ \\
$\mathbf{3}$ & $>1,6 \times 10^{5}$ & $>1,6 \times 10^{5}$ & $2,1 \times 10^{5}$ \\
$\mathbf{4}$ & $>1,6 \times 10^{5}$ & $4,3 \times 10^{4}$ & $6,1 \times 10^{5}$ \\
\hline Ponto C & & & \\
\hline $\mathbf{1}$ & $4,8 \times 10^{3}$ & $2,8 \times 10^{4}$ & $6,8 \times 10^{4}$ \\
$\mathbf{2}$ & $>1,6 \times 10^{5}$ & $>1,6 \times 10^{5}$ & $3,5 \times 10^{5}$ \\
$\mathbf{3}$ & $>1,6 \times 10^{5}$ & $4,7 \times 10^{3}$ & $1,9 \times 10^{5}$ \\
$\mathbf{4}$ & $>1,6 \times 10^{5}$ & $>1,6 \times 10^{5}$ & $7,6 \times 10^{5}$ \\
\hline $\mathbf{X}$ & $9,9 \times 10^{4}$ & $8,2 \times 10^{4}$ & $3,2 \times 10^{5}$ \\
\hline F & & & \\
\hline 0 & & & \\
\hline
\end{tabular}

Fonte: O autor, 2015.

UFC: Unidades Formadoras de Colônias*CT- Coliformes

Totais **CTT- Coliformes Termotolerantes

A Agência Nacional de Vigilância Sanitária do Ministério da Saúde (ANVISA), de 2 de Janeiro de 2001, na Resolução RDC $\mathrm{n}^{\circ} 12$, estabelece para hortaliças frescas, refrigeradas ou congeladas, o limite de tolerância do NMP de Coliformes Termotolerantes de no máximo $1 \times 10^{2}$ NMP/g(BRASIL, 2001). De acordo com esses padrões microbiológicos sanitários para alimentos destinados ao consumo humano, as alfaces analisadas estão impróprias para o consumo, sendo constatada inclusive a presença de Escherichia coli, indicando que houve contaminação de origem fecal.

Como mostra a tabela 1 os microorganismos aeróbios mesófilos tiveram variação de, $4,5 \times 10^{4} \mathrm{UFC} / \mathrm{g}$ a $7,7 \times 10^{5} \mathrm{UFC} / \mathrm{g}$ com média $3,2 \times 10^{5} \mathrm{UFC} / \mathrm{g}$, demonstrado que as alfaces estão com alto grau de contaminação.Resultados semelhantes foram observados no trabalho realizado na cidade de Uberlândia, avaliando a qualidade higiênica sanitária de alfacescomercializadas em feiras livres, que apresentaram elevada contaminação de micro-organismos aeróbios mesófilos, com números superiores a $10^{6}$ $\mathrm{UFC} / \mathrm{g}$, indicando possível presença de microorganismos patógenos, resultante da falta, ou falha de higiene na obtenção e manuseio do produto (FRANÇA; BONNAS; SILVA, 2014).

Das doze amostras analisadas foram isoladas 80 cepas, todas da família Enterobacteriaceae. A família Enterobacteriaceae é uma das mais importantes famílias bacterianas, compreende o ser vivo mais conhecido a Escherichia coli, pertencente à microbiota intestinal, tanto de seres humanos quanto de animais de sangue quente, constituem a principal causa de infecção intestinal em muitos países (KAPER; NATARO; MOBLEY, 2004). 
Segundo Tortora, Funk e Case (2012) a presença de Escherichia coli na água e nos alimentos é uma indicação de contaminação fecal. Portanto pode-se afirmar que, em algum momento seja na produção, transporte, armazenamento ou manipulação das alfaces, houve contato com fezes de origem humana e/ou animal.

Como mostra a Figura 1, das 80 cepas isoladas 30\% foram Klebsiella pneumoniae, 10\% Providencia alcalifaciens e Enterobactersp., também foi constatada a presença de Escherichia coli. Os gêneros Enterobacter e Klebsiella são frequentemente utilizados como indicadores das condições sanitárias e do controle da qualidade de água e alimentos (SOUZA, 2006).
Figura 1 - Distribuição das cepas da família Enterobacteriaceae identificadas nas amostras de alfaces comercializadas em feiras livres no município de Sobral - CE.

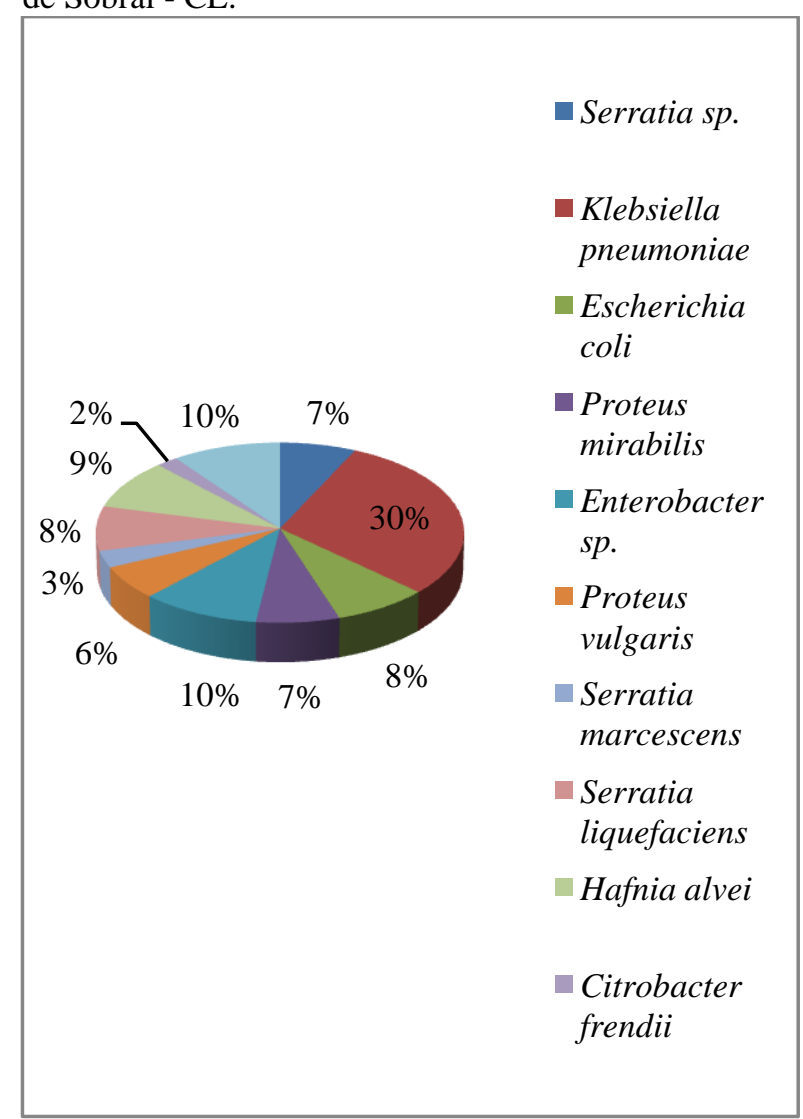

Fonte: O autor, 2015.

$\mathrm{Na}$ análise parasitológica foi possível observar que $91 \%$ das amostras apresentaram contaminação por parasitas e alto grau de sujidades, mostrando que há falhas na higienização das mesmas no momento da colheita, do armazenamento e no ambiente de venda. Em apenas $41 \%$ das amostras houve contaminação mista, contendo dois ou mais parasitas diferentes (Tabela 2).

Resultados obtidos por Ramos et al.(2014)nas amostras de alface comercializadas em Umuarama - PR o índice de contaminação por parasitos foi baixo, visto que apenas $7,5 \%$ das amostras estavam contaminadas, valores muito inferiores ao encontrado no atual estudo. 
Tabela 2 - Prevalência de parasitas em alfaces comercializadas em feiras livres no município de Sobral - CE.

\begin{tabular}{|c|c|c|c|}
\hline \multicolumn{2}{|c|}{ AMOSTRAS } & \multicolumn{2}{|c|}{ PARASITOS } \\
\hline & Ponto A & Ponto B & Ponto C \\
\hline 1 & $\begin{array}{c}\text { Entamoeba sp. } \\
\text { Lavras de } \\
\text { nemotoides } \\
\text { Giardia lamblia } \\
\text { Ascaris sp. }\end{array}$ & $\begin{array}{c}\text { Entamoeba } \\
\text { sp. } \\
\text { Ascaris sp. }\end{array}$ & $\begin{array}{l}\text { Lavras de } \\
\text { nematoides }\end{array}$ \\
\hline 2 & Ascaris sp. & Ascaris sp. & $\begin{array}{l}\text { Lavras de } \\
\text { nematoides } \\
\text { Ascaris sp. }\end{array}$ \\
\hline 3 & $\begin{array}{c}\text { Larvas de } \\
\text { nematoides }\end{array}$ & ------------- & $\begin{array}{l}\text { Larvas de } \\
\text { nematoides }\end{array}$ \\
\hline 4 & $\begin{array}{c}\text { Amebas } \\
\text { Ascaris sp. } \\
\text { Lavras de } \\
\text { nematoides }\end{array}$ & $\begin{array}{l}\text { Lavras de } \\
\text { nematoides } \\
\text { Ascaris sp. }\end{array}$ & Ascaris sp. \\
\hline
\end{tabular}

Fonte:O autor, 2015.

Observa-se na figura 2 que os parasitas mais frequentemente encontrados foram os Ascaris sp. presente em $67 \%$ das amostras, seguido de larvas de nematoide observado em $50 \%$, pode-se também observar em $17 \%$ das a amostras presença de Entamoeba sp. Os parasitas menos prevalentes foram Giárdia lamblia e Ameba. Segundo Neves et al. (2005) a contaminação de vegetais frescos por Giárdia lamblia, Entamoeba histolytica, e Ascaris sp. geralmente ocorre antes da colheita, usualmente como resultado da água de irrigação contaminada e práticas de higiene insuficientes.
Figura 2 - Percentual de parasitas observado em amostra de alfaces comercializadas em feiras livres no município de Sobral - CE

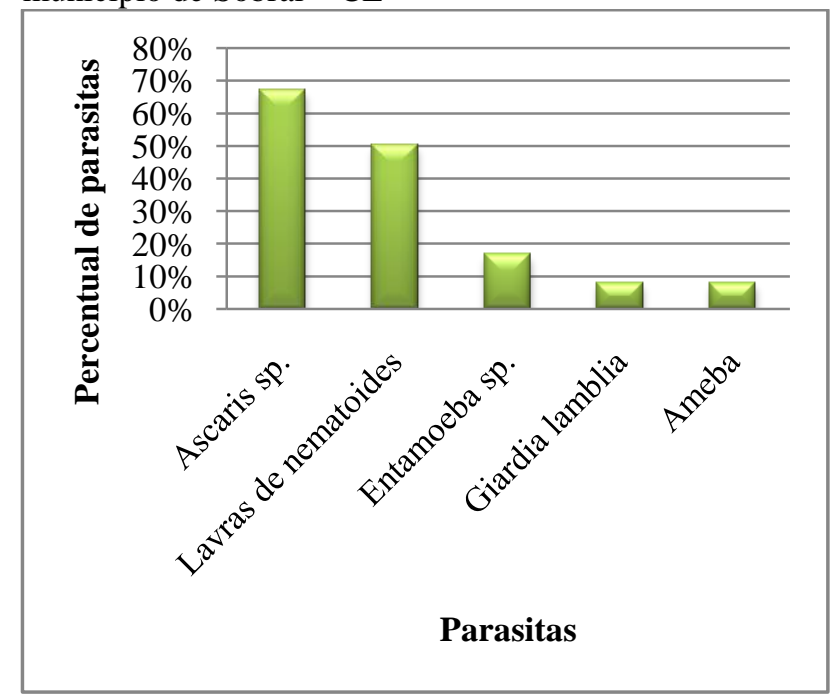

Fonte: O autor, 2015.

Em estudo realizado por Santos (2012) para detecção de estruturas de enteroparasitas em amostras de alfaces comercializadas em Campina Grande, foipossível observar presença de Entamoeba sp., larvas de nematoide, Giardia sp. e Ascaris sp. valores semelhantes aos apresentados nesse trabalho, evidenciando a frequente presença desses parasitas em hortaliças, sendo necessário maior atenção a correta higienização antes do consumo.

A Agência Nacional da Vigilância Sanitária, na Resolução da Comissão Nacional de Normas e Padrões para Alimentos - CNNPA (BRASIL, 1978), regulamenta que as hortaliças devem estar ausentes de sujidades, parasitas e larvas. Neste contexto, as hortaliças pesquisadas estão em desacordo com essa norma, ou seja, em condições higiênicas sanitárias irregulares para o consumo. 


\section{CONCLUSÃO}

Conclui-se que as alfaces comercializadas em feiras livres no município de Sobral apresentam uma baixa qualidade higiênico-sanitária, que se deve ao não cumprimento das exigências no que diz respeito às boas práticas de higiene $\mathrm{e}$ manipulação de alimentos. Foi detectada

\section{REFERÊNCIAS}

BLODGETT, R. Most Probable Number from Serial Dilutions. In US FOOD AND DRUG ADMINISTRATION (FDA), Bacteriological Analytical Manual Online. Revision July 2003. Disponível em:

<http://www.fda.gov/Food/FoodScienceResea rch/LaboratoryMethods/ucm2006949.htm>.

Acesso em: 19 mai. 2014.

BOBCO, S. E.; PIEROZAN, M. K.;

CANSIAN, R. L.; OLIVEIRA, D.;

PINHEIRO, T. L. F.; TONIAZZO, G.

Condições higiênicas de alfaces (Lactuca

sativa) comercializadas na cidade de

Erechim-RS. Alimentação e Nutrição.,

Araraquara, v.22, n.2, p.301-305, 2011.

BRASIL. Comissão Nacional de Normas e Padrões para Alimentos - CNNPA / ANVISA

- Agência Nacional da Vigilância Sanitária.

Normas técnicas especiais, n.12, de 1978.

São Paulo, 1978. Disponível em: <

http://www.rebrae.com.br/banco_arquivos/arq inclusive, a presença de Escherichia coli, sendo necessária à adoção de medidas, por parte dos órgãos de vigilância sanitária, para melhoria da qualidade higiênica dessa hortaliça alertando os produtores e consumidores a correta higienização, a fim de diminuir a transmissão de doenças veiculadas por alimentos contaminados.

uivos/nutricao/12_78.pdf>. Acesso em: 20 jul. 2014.

BRASIL. Ministério da Saúde. Agência Nacional de Vigilância Sanitária (ANVISA). Resolução RDC n ${ }^{\circ} 12$, de 02 de janeiro de 2001. Regulamento técnico sobre os padrões microbiológicos para alimentos.

Diário Oficial da Republica Federativa do Brasil, seção 1, p.45-53. Disponível em: $<$ http://www.anvisa.gov.br/legis/resol/12_01r dc.htm.> Acesso em: 20 jul. 2014.

COSTANTIN, B. D. S.; GELATTI, L. C.; DOS SANTOS, O. Avaliação da contaminação parasitológica em alfaces: Um estudo no sul do Brasil. Revista Fasem

Ciências, v. 3, n. 1, p. 1-14, Jan-Jun, 2013. FENG, P.; WEAGANT, S. D.; GRANTE, M. A. Enumeration of Escherichia coli and the coliform bacteria, 2002. In: Food and drug administration-FDA/CF-SAN.

Bacteriological analytical anual oline.

Disponível em: 
<http://www.fda.gov/Food/FoodScienceResea rch/LaboratoryMethods/ucm064948.htm> Acesso em: 19 mai. 2014.

FERNANDES, A. A.; MARTINEZ, H. E. P.; PEREIRA, P. R. G.; FONSECA, M. C. M. Produtividade, acúmulo de nitrato e estado nutricional de cultivares de alface, em hidropônica, em função de fontes de nutrientes. Horticultura Brasileira, Brasília, v.20, n.2, p.195-200, junho 2002.

FRANÇA, B. R.; BONNAS, D. S.; SILVA, C. M. de O. Qualidade higiênica sanitária de alfaces (lactuca sativa) comercializadas em feiras livres na cidade de Uberlândia-MG, Brasil. Bioscience Journal, Uberlândia, v.30, supplement 1, p.458-466, junho, 2014.

FRANCO, B. D. G. M.; LANDGRAF, M. T. D. Microbiologia dos alimentos. São Paulo, Ed. Atheneu, 2008. 182 p.

JAKABI, M.; FRANCO, B. D. M. Frequência de isolamento de cepas de E.coli patogênicas em alimentos de origem animal. Ciência e Tecnologia de Alimentos. Campinas, v.11, n. 1, p. 170-181, 1991.

KAPER, J. B.; NATARO, J. P.; MOBLEY, H. L. T. Pathogenic Escherichia coli.Nature Reviews Microbiology, v.2, n.2, p. 40-123, feb, 2004.

KONEMAN, E. W.; ALLEN, S. D.; JANDA, W.; WINN, W.Jr.; PROCOP, G.;

SCHRECKENBERGER, P.; WOODS, G.

\section{Diagnóstico Microbiológico: texto e atlas}

colorido. $6^{\text {a }}$ ed. Guanabara Koogan, 2008. $1760 \mathrm{p}$.

MAISTRO, L. C. Alface minimamente processada. Revista de Nutrição, São Paulo, v.14, n.3, p. 119-224, set./dez, 2001.

NASCIMENTO, A. R.; MOUCHREK FILHO, J. E.; MOUCHREK FILHO, V. E.; MARTINS, A. G. L. A.; MARINHO, S. C.; SERRA, C. L. M.; ALVES, L. M. C. Avaliação da sensibilidade de antimicrobianos a cepas de enterobacteriaceae isoladas de amostras de alface (Lactuca sativa) comercializada na cidade de São LuísMA. Boletim do Centro de Pesquisa e Processamento de Alimentos, Curitiba, v.23, n.2, p. 265-272, jul./dez, 2005.

NEVES, D. P.; MELO, A. L.; LINARDI, P. M,; VITOR, R. W. A. Parasitologia Humana: Helmintos. 11a ed. São Paulo: Atheneu, 2005. 494 p.

OLIVEIRA, C. A. F. de; GERMANO, P. M. L. Estudo da ocorrência de Enteroparasitas em hortaliças comercializadas na região metropolitana de São Paulo - SP, Brasil. II Pesquisa de Protozoários Intestinais. Revista de Saúde Pública, v.26, n.5, p.332-335, 1992.

PERES JUNIOR, J.; GONTIJO, E. E. L.; SILVA, M. G. Perfil parasitológico e microbiológico de alfaces comercializadas em restaurantes self-service de Gurupi-TO. 


\section{Revista Científica do Instituto}

Tocantinense Presidente Antônio Carlos

(ITPAC), v.5, n.1, p.1-8, 2012.

RAMOS, M. de O.; BEGOTTI, I. Z.; ROSA, G da.; VIEIRA, G. F. P.; MESSA, V.;

MERLINI, L. S. Avaliação parasitológica de alfaces (Lactuca sativa) comercializadas no município de Umuarama, Paraná, Brasil.

\section{Revista Brasileira de Higiene e Sanidade}

Animal, v. 08, n. 3, p. 1-12, jul-set, 2014.

SANTANA, L. R. R. de; CARVALHO, R. D.

S.; LEITE, C. C.; ALCÂNTARA, L. M.;

OLIVEIRA, T. W. S. de; RODRIGUES, B.

da M. Qualidade física, microbiológica e parasitológica de alfaces (Lactuca sativa) de diferentes sistemas de cultivo. Ciências e Tecnologia de Alimentos, Campinas, v.26, n.2, p. 264-269, abr/jun, 2006.

SANTOS, G. L. D. dos; Detecção de estruturas de enteroparasitas em amostras de alfaces (Lactuca sativa) comercializada em Campina Grande, Paraíba - 2012. 18f. Trabalho de conclusão de curso (Graduação em Farmácia) - Universidade Estadual de Paraíba, Centro de Ciências Biológicas e da Saúde, 2012.

SILVA, L. P.; SILVA, E. J.; SILVA, R. M. G. Diagnóstico parasitológico de Horticultores no monitoramento da contaminação parasitária em ambientes rurais. Bioscience Journal,Uberlândia, v.26, n.4, p.648-652, 2010.
SILVA, N.; JUNQUEIRA, V. C. A.;

SILVEIRA, N. F. A. Manual de métodos de análise microbiológica de alimentos. $2^{\mathrm{a}} \mathrm{ed}$, São Paulo: Livraria Varela, 2001. 229 p.

SOUZA, C. P. Segurança alimentar e doenças veiculadas por alimentos: utilização do grupo coliforme como um dos indicadores de qualidade de alimentos. Revista de Atenção Primária à Saúde, v.9, n.1, p. 83-88, jan/jun, 2006.

TEIXEIRA, L. E. B.; SANTOS, J. E. F dos.; MOREIRA, I. dos S.; SOUSA, F. C de.; NUNES, J. S. Qualidade microbiológica de frutas e hortaliças comercializadas na cidade de Juazeiro do Norte - CE. Revista Verde (Mossoró - RN - Brasil), v.8, n.3, p.23-26, jul - set, 2013.

TORTORA, G. J.; FUNKE, B. R.; CASE, C. Microbiologia. 10. ed. Porto Alegre. Artmed, 2012. $310 \mathrm{p}$.

XAVIER, A. Z. P.; VIEIRA, G. D. G.; RODRIGUES, L. O. M.; VALVERDE, L. O.; PEREIRA, V. S. Condições higiênicosanitárias das feiras-livres do município de Governador Valadares. Governador

Valadares - MG: UNIVALE, 2009.

Trabalho de Conclusão de Curso de nutrição, Faculdade de Ciência da Saúde - FACS, Universidade Vale do Rio Doce, 2009. 